This article was downloaded by: [Australian National University]

On: 24 J une 2014, At: 19:43

Publisher: Routledge

Informa Ltd Registered in England and Wales Registered Number: 1072954 Registered

office: Mortimer House, 37-41 Mortimer Street, London W1T 3J H, UK

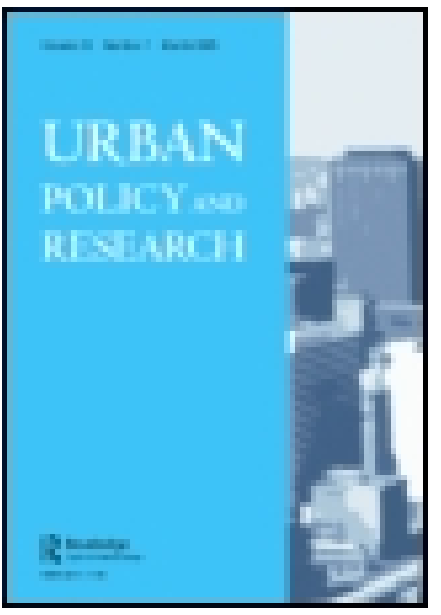

\title{
Urban Policy and Research
}

Publication details, including instructions for authors and

subscription information:

http:// www.tandfonline.com/loi/ cupr20

\section{Reclaiming Indigenous Planning}

\author{
Ed Wensing ${ }^{a}$ \\ ${ }^{a}$ National Centre for Indigenous Studies, Australian National \\ University, Canberra, Australia \\ Published online: 20 J un 2014.
}

To cite this article: Ed Wensing (2014): Reclaiming Indigenous Planning, Urban Policy and Research, DOI: $10.1080 / 08111146.2014 .926583$

To link to this article: http:// dx. doi.org/ 10.1080/08111146.2014.926583

\section{PLEASE SCROLL DOWN FOR ARTICLE}

Taylor \& Francis makes every effort to ensure the accuracy of all the information (the "Content") contained in the publications on our platform. However, Taylor \& Francis, our agents, and our licensors make no representations or warranties whatsoever as to the accuracy, completeness, or suitability for any purpose of the Content. Any opinions and views expressed in this publication are the opinions and views of the authors, and are not the views of or endorsed by Taylor \& Francis. The accuracy of the Content should not be relied upon and should be independently verified with primary sources of information. Taylor and Francis shall not be liable for any losses, actions, claims, proceedings, demands, costs, expenses, damages, and other liabilities whatsoever or howsoever caused arising directly or indirectly in connection with, in relation to or arising out of the use of the Content.

This article may be used for research, teaching, and private study purposes. Any substantial or systematic reproduction, redistribution, reselling, loan, sub-licensing, systematic supply, or distribution in any form to anyone is expressly forbidden. Terms \& Conditions of access and use can be found at http://www.tandfonline.com/page/termsand-conditions 


\title{
Book Review
}

\author{
Reclaiming Indigenous Planning \\ Ryan Walker, Ted Jojola \& David Natcher \\ Montreal, McGill-Queen's University Press, 2013, 524pp., ISBN 9780773541948
}

This book derives from the proceedings of an International Roundtable on Indigenous Community Planning and Land Use Management that was held in Saskatchewan, Canada in June 2010. The Roundtable's goal was to continue reconnecting past practice with present circumstances in the context of planning for the future in Indigenous communities and the book's goal is to reclaim and reassert Indigenous planning as a necessary field of scholarship and planning practice.

The Roundtable brought together leading Indigenous and non-Indigenous scholars and practitioners from Canada, New Zealand, the USA and Australia to examine the opportunities and obstacles facing Indigenous peoples in these four Western countries as they work to enact positive change in their home communities and territorial lands. The majority of the chapters are from participants of the Roundtable. In compiling the book, the editors also invited additional scholars and practitioners who were not at the Roundtable to contribute in order to present the best possible depth and breadth of wisdom in the field. As a result, the authors are from among the most well versed and experienced in working for and with Indigenous communities in the four countries with relatively similar British colonial origins. Their efforts are premised on informing solutions in a culturally appropriate manner, as well as empowering Indigenous communities to make their own decisions. As the editors say, this approach has been characterised among Maori people as "walking backwards into the future" (Kingi, 2010, cited on, p. xix). "In other words, to plan meaningfully for the future, one must respect and build upon the past" (p. xix), a point which seems to be lost on the dominant societies in each of the four countries analysed in this book.

As the editors state, the chapters are diverse both geographically and thematically. Geographically they cover areas as far apart as the Canadian Arctic and the deserts of Australia. Thematically the wide range of topics explored include Indigenous mobilisation and forms of resistance, awareness raising and visioning in Indigenous communities; Indigenous participation in community planning processes; forms of governance internal to Indigenous communities, across affiliated communities and at the state-community interface; and the practice of Indigenous planning presented through case studies, personal narratives and critiques of 'state' planning practices (p. xix).

The book is structured into three parts with an opening chapter setting the scene for the book's focus on planning practice as both a professional and scholarly discipline and a final chapter summing up the challenges to reclaiming Indigenous planning. 
The first chapter by Hirini Matunga from New Zealand sets the scene by tracing a conceptual framework for Indigenous planning which links the past, present and the future to the ongoing and active participation of Indigenous communities in their own planning (pp. 3-32). The concluding chapter by Ted Jojola discusses the ethical, methodological and epistemological approaches to community planning design and planning by Indigenous communities, identifying the tenets and challenges to reclaiming Indigenous planning and arguing that the seven generations model is at the heart of sustainability for Indigenous communities (pp. 457-472).

The intervening chapters relate to three broad areas for conceptualising and reclaiming Indigenous planning. The six chapters in the first part of the book focus on the central importance of Indigenous community values, traditions and their exercise of self-determination in the conceptualisation of planning as a set of future-seeking processes. The five chapters in the second part of the book address the emergence of urbanisation and urbanism as a key dimension of modern life for Indigenous communities because in all four countries of analysis in this book, the majority of Indigenous peoples live in urban areas and growing numbers of Indigenous people are being born in cities and are not living on reserves or in remote communities on their traditional lands. The seven chapters in the third part of the book discuss Indigenous peoples' stewardship of lands and resources that has been a significant part of their cultural practices for centuries or millennia, "an imperative that persists, though in dynamic tension with modern economic pressures towards land and resource development" (p. xxii).

There are several chapters exploring issues in Canada with fewer chapters focusing on similar issues and experiences in Australia, New Zealand and the USA.

The three chapters by Australian authors explore why Indigenous rights and interests in urban planning are less prominent than in environmental and natural resources planning outside the city and how these omissions are reconstituting the relationships of coexistence between Indigenous peoples and the state in both Canada and Australia (pp. 282-310); challenge the widespread perception that capacity deficits in natural resource management (NRM) systems reside only with Indigenous peoples and argue that they may well be with the state (pp. 313-338); and examine the use of Indigenous facilitators funded by the Australian government as a communication link between Indigenous and non-Indigenous landholders and stakeholders in regional NRM and governance (pp. 396-413).

Two chapters from New Zealand authors draw lessons about how Maori approaches and knowledge can be incorporated into local planning processes by examining a major subdivision development undertaken by the Ngai Tahu tribe on New Zealand's south island as a case study (pp. 236-259); and how formal integrated decision support frameworks can be utilised to link Indigenous knowledge with Western science and industry knowledge to evaluate and design land use options that have the potential to balance multiple outcomes and confer functional integrity (pp. 339-356).

Three chapters from US authors show that recent gains in greater self-determination and sovereignty by Indigenous peoples has not been met with parallel or comparable gains in socio-economic standing and demonstrate using a case study approach that the "cruel choice' between culture and economy continues to persist (pp. 94-112); Indigenous communities should not be shifted by well-meaning outside planners from determining 
what is best for their communities and their future because Indigenous communities will often make decisions about participating in externally driven regional planning processes based on a number of factors that are not immediately apparent to other participants (pp. 166-190).

The chapters from Canadian authors cover a diverse range of topics in each of the three broad areas and the themes mentioned above.

I am not aware of any comparable edited volume of papers of such depth and breadth that analyses approaches to Indigenous planning practice and scholarship across these four countries. Hence, this book is a remarkable collection and makes a very valuable contribution to the field of planning theory and practice with respect to Indigenous peoples' values and aspirations and their just accommodation in contemporary planning. It also sets a high benchmark for future comparable reference.

A number of chapters stand out for their analysis and pertinent observations that are equally applicable in other jurisdictions. In addition to the first and last chapters discussed above, there are three 'standout' chapters.

Stephen Cornell's chapter on "Reconstituting Native Nations: Colonial Boundaries and Institutional Innovation in Canada, Australia and the United States" (pp. 35-59) which explores how Indigenous peoples in Canada, the USA and Australia have been trying to reassert their rights to self-determination and reclaiming the right to shape their own futures by "rethinking the boundaries - the units - by which power itself is organised" (p. 36), enacting "their own conceptions of self-determination and self-governance" (p. 41) and "building new organisational foundations for action" (p. 53). Cornell argues that social boundaries are merely human constructs and that colonialism had two sequentially relayed impacts on Indigenous boundaries: disruption and rigidification as the outsiders imposed their preferred boundaries, expropriating lands and organising Indigenous people. Cornell concludes that "For far too long, other entities, other powers, insisted on answering questions for Indigenous peoples" and that they are now "answering those questions for themselves" (p. 53) and they are "rejecting, subordinating, superseding, or reimagining" (p. 43) the boundaries that the colonisers created. The new organisations are "not only about asserting Indigenous identities or rejecting colonial boundaries" they are also about "practical problem solving" and providing "bases for (transformative) planning from a new and largely Indigenously determined starting point" (p. 52).

This theme of boundary legacies is further explored by Cathy Robinson and Marcus Lane's chapter on "Boundary-Riding: Indigenous Knowledge Contributions for Natural Resource Decision Making in Northern Australian Regions" (pp. 396-413) which explores the ways in which Indigenous knowledge is being integrated into NRM programmes in northern Australia through the use of 'facilitators' to 'broker' Indigenous participation in regional natural resource planning and management arrangements. The authors note that policy formation theories emphasise the cognitive and discursive aspects and that knowledge exchange and translation "is not an apolitical one-way process". Imported Western planning rationalities are slowly being "decoded, recalled and renegotiated on the ground" (p. 406). Regional NRM planners and facilitators are reporting frustrations with having to deal with problems involved in mediating between 'top-down' and 'bottom-up' planning agendas, and that if Indigenous people are to engage in sharing and developing the knowledge that underpins NRM decisions then brokering efforts need to better manage the causal 
relationships between the different knowledge contributions and claims and "critical attention needs to be paid to the extent to which Indigenous Australians can gain access to shaping public policy goals and outcomes, and the degree to which they are given control over resources needed to deliver these planning objectives" (p. 407). The problems the 'boundary riders' are encountering demonstrate that the "impasse is not yet resolved" and that navigating them "requires recognition that the epistemological borders also mark deeper ideological and cultural cleavages" that are "less easily crossed" (p. 408).

The third standout chapter is by Leonie Sandercock and Giovanni Attili, "The Past as Present: Film as a Community Planning Intervention in Native/Non-Native Relations in British Columbia, Canada”, which documents and discusses the authors' work with two First Nations communities in north-central British Columbia and their journey from colonisation to revitalisation and on to partnerships in economic and social development with non-Native neighbours. The project involved the making of a documentary in collaboration with the two First Nations communities and the chapter explores the why and how of the use of film as a catalyst for difficult conversations in a historic and deeply divided community and the outcomes. The communities were intimately and integrally involved in the making of the film and the authors "consciously designed a postproduction community dialogue" and used the film as "a catalyst for social change processes" (p. 87). The authors were inspired "to turn the gaze back upon settler society, to break through the massive culture of denial and the veil of ignorance: to name the violence, to face the history" and to "unsettle this settler society", concluding that "paradigm shifts" can occur through small but courageous steps based on local conditions (p. 88).

The book is peppered with pertinent observations and extraordinary experiences. However, I agree with the author of the Foreword, Aaron Aubin, that the book should act as a catalyst for change in the way planners engage with Indigenous communities, the way public policy is developed, the way universities develop their educational curriculum and the way society thinks about Indigenous peoples (p. xvi).

I can't speak for the other jurisdictions, but in Australia the issue of incorporating Indigenous issues into our university planning courses has been on the agenda for several years. In 2007, the Planning Institute of Australia (PIA) formed the Indigenous Planning Working Group (IPWG) to raise awareness of Indigenous peoples' values and aspirations in planning contexts and to improve planning education. In 2010, the IPWG released a Discussion Paper on “Improving Planners' Understanding of Aboriginal and Torres Strait Islander Australians and Recommendations for Reforming Planning Education Curricula for PIA Accreditation" (Indigenous Planning Working Group, 2010). The paper went down like a lead balloon and the Working Group has since disbanded due to lack of support and general disinterest in pursuing the recommendations in the Discussion Paper. Perhaps we need a compendium of experiences with a particular focus on Australia similar to this one to wake the profession from its colonial slumber.

If this edited volume has any weakness, it is the predominant focus on Canada over the other three countries, but that is understandable given the origins of the book.

As a practitioner, academic and research scholar, I will be using this book as a benchmark and recommending this as compulsory reading for my students and fellow practitioners. 


\section{Reference}

Indigenous Planning Working Group (2010) Improving Planners' Understanding of Aboriginal and Torres Strait Islander Australians and Recommendations for Reforming Planning Education Curricula for PIA Accreditation, A Discussion Paper. Available at http://www.planning.org.au/documents/item/2381

\section{Ed Wensing \\ National Centre for Indigenous Studies} Australian National University, Canberra, Australia

Edward.Wensing@anu.edu.au

(C) 2014, Ed Wensing

http://dx.doi.org/10.1080/08111146.2014.926583 